\title{
Los jóvenes y el cambio climático. Una práctica etnometodológica
}

\author{
Susana Gómez Loperena ${ }^{1 *}$, Guadalupe Alicia Cavazos Velázquez², Luis Erubiel Molina \\ Arredondo ${ }^{3}$
}

\section{Resumen}

El artículo describe el comportamiento y la capacidad reflexiva de los actores-investigadores femenino y masculino como seleccionadores de noticias mediáticas sobre el cambio climático y como emisores de dichas publicaciones en Facebook. Se aporta el diseño experimental de práctica etnometodológica de comunicación virtual con experiencias disruptivas, mediante la publicación de tres noticias diarias, durante tres semanas, a un grupo de 12 contactos directos de cada emisor en Facebook. Ante las 63 publicaciones sobre el cambio climático, la respuesta fue de rechazo en los receptores; de incertidumbre, desconcierto y temor en los actores-investigadores, quienes privilegiaron los temas de contaminación, cambio climático y políticas públicas.

\section{Abstract}

This article describes the behavior and reflective capacity of male and female actors-researchers as media news selectors on climate change and issuers of such publications on Facebook. The experimental design of the ethnomethodological practice of virtual communication with disruptive experiences is provided, through the publication of three daily news, for three weeks to a group of 12 direct contacts of each sender on Facebook. The response towards the 63 publications on climate change, mainly prioritizing topics such as pollution, climate change and public policies, was of rejection by recipients, and of uncertainty, bewilderment and fear by the actors-researchers.

\section{Palabras Clave}

Etnometodología, Cambio climático, Género

Keywords

Ethnomethodology, Climate change, Gender

${ }^{1}$ Maestra en Administración Pública. Universidad Autónoma de Tamaulipas, México.

${ }^{2}$ Maestra en Ciencias de la Comunicación. Universidad Autónoma de Tamaulipas, México.

${ }^{2}$ Maestro en Ciencias de la Comunicación. Universidad Autónoma de Tamaulipas, México.

*Autor para correspondencia: susana.loperena@gmail.com

\section{Introducción}

En este trabajo se propone un diseño de práctica etnometodológica con perceptores femeninos y masculinos que seleccionaron en total 126 noticias mediáticas sobre fenómenos del cambio climático y ejercieron la función de líderes de opinión en Facebook ante un grupo de 12 receptores directos cada uno, a quienes les publicaron en sus muros el mensaje mediático. Los actores-investigadores, siguiendo la etnometodología, aplicaron la reflexividad en el análisis de sus prácticas de experiencias disruptivas de comunicación.

Las ciencias de la comunicación sirven a la comprensión, diagnóstico e intervención social con la finalidad de "producir un saber a la vez transdisciplinario y accesible a la gente" y "desarrollar un discurso del método asociado a la práctica de la intervención, y la construcción de espacios de intervención" (Vizer, 2003, p. 17). 
Los sujetos sociales crean la realidad comunicativa donde interactúan y se comunican, los investigadores de la comunicación buscan conciliar las interpretaciones de la realidad del actor-investigador con su sujeto de observación, desde el papel de las subjetividades en la comunicación intersubjetiva. Así "la realidad como construcción es un producto de la subjetividad e intersubjetividad del ser humano y en ella, éste configura su propio universo, basándose en percepciones, significaciones, la contingencia y la probabilidad" (Builes y Gutiérrez, 2017, p. 264).

El estudio microsocial de la comunicación con sus particularidades y coyunturas, permite la comprensión del sentido interpretativo de la realidad según los sujetos estudiados y la reflexividad del actor-investigador participante. Así, para explorar los procesos de comunicación de los actores que interpretan y construyen la realidad, es necesario usar los mapas conceptuales, el lenguaje y modos de interacción de los sujetos estudiados a partir de las necesidades metodológicas del investigador donde "los procesos de construcción de dominios sociales o de sus territorios y de sus respectivos mapas de sentido se inaugura con el descubrimiento del inconsciente y el reconocimiento de la validez de investigar los procesos de subjetividad" (Vizer, 2003, p. 98).

Es necesario agregar que los procesos de subjetividad individual se cruzan con los procesos de creación de realidades comunicativas emprendidas por los medios masivos de comunicación que forman cosubjetividades colectivas, al establecer agendas informativas dirigidas a públicos específicos "en una cotidianidad que conduce a la producción y reproducción de discursos, determinados tanto por los MCS masivos como por la relación de sus mensajes con repertorios y esquemas mentales y de acción propios" (Piñuel y col., 2011, p. 3, 4).

En la actual Sociedad de la Información y Comunicación, los medios masivos de comunicación, el Internet y las redes sociales digitales, configuran realidades comunicativas donde se mezclan las visiones de la realidad surgidas desde los polos de la subjetividad, la intersubjetividad, la cosubjetividad colectiva o social y la comunicativa-mediática "como foro para discursos de otros y como orador por derecho propio, los medios de comunicación son una parte clave en la producción y transformación de significados" (Carvalho, 2009, p. 27).
Las sociedades modernas son atravesadas por dos temas prioritarios para el desarrollo humano, el cambio climático y la perspectiva de género, ambos con agendas temáticas poco difundidas desde los medios masivos de comunicación y en ocasiones mal entendidos e incluso ignorados por el gran público, esto crea un campo donde "deben estudiarse las prácticas humanas (incluidas las cognoscitivas) que han permitido a los grupos de investigadores o de actores eruditos acordar sus conocimientos, negociar sus métodos y evidenciar sus empiricidades sobre el denominado fenómeno del cambio climático" (Arellano, 2014, p. 114).

Al revisar subjetividades e intersubjetividades, los modelos de construcción de la realidad femenina y masculina marcan diferencias sustanciales que se traducen en modos perceptivos, conductuales y de relación social diferenciado entre mujeres y hombres, como lo expresa la perspectiva de género, "la percepción es individual, es significativa y (...) social. (...) diferenciada socialmente, (...) por el género. Existen representaciones de los sentidos y un uso (...) que se asocian con hombres o con mujeres, e inclusive formas perceptivas genéricamente diferenciadas" (Sabido, 2016, p. 78).

En el estudio de la comunicación del cambio climático con perspectiva de género "la flexibilidad que caracteriza a la investigación cualitativa permite probar novedosas teorías respecto a las variables que explican la percepción a cierto tema socioambiental", tomando en cuenta variables como nivel educativo, "género, con los elementos subjetivos del individuo: sentimientos e imágenes, etc. frente al cambio climático" (Retamal y col., 2011, p. 188).

Dentro del enfoque cualitativo de investigación se optó por aplicar la etnometodología que considera "el único objeto de estudio posible son las producciones sociales de sentido. Es decir, la observación de la manera en que los actores ven, describen y explican su hacer y el medio en el que viven" (Vela y Cantamutto, 2016, p. 4). Para lograrlo es necesario que el actor social reconozca las reglas ocultas que guían su comportamiento comunicativo y social, esta es una tarea complicada porque "(... ) el individuo define las situaciones, genera una idea y actúa conforme a ellas ante los hechos sociales. Crea un contexto en el que interviene otro sujeto con sus propias interpretaciones e ideas, pero ninguno de los dos es consciente" (Fernández y Tardivo, (2016, p. 137). 
Para visibilizar la cultura dentro de la intersubjetividad, la etnometodología propone la realización de prácticas de experiencias disruptivas que demuestran cómo "la visibilidad del orden social se genera en momentos de ruptura destacables por mostrar cierto tipo de desviación respecto al curso normal de los acontecimientos" (Sánchez y Fele, 2015, p. 18, 19).

Rompiendo la expectativa del comportamiento aceptado como normal o propio del sentido común. Esta situación provoca conflictos evidentes donde los actores ven fracasar sus expectativas y denuncian al otro actor como causante de esta falla en la comunicación del sentido común aplicado a la cotidianidad donde opera "la conciencia del actor de sus opciones, (...) su capacidad de anticipar como van a reaccionar los otros (...) dispone el orden en el mundo cotidiano. La explicación es el proceso por el que las personas dan sentido al mundo" (Salcedo, 2015, p. 33). Son estas narraciones de la experiencia planeada y la experiencia vivida, con sus diferencias en el mundo de la cotidianidad, lo que permite la ejecución de la reflexividad del actor.

Para ejecutar la reflexividad sobre la subjetividad cognitiva y afectiva, el actor-investigador necesita de la respuesta comunicativa cognitiva y afectiva de otro sujeto (actor receptor) para poder apreciar su propia subjetividad en la reacción provocada por la retroalimentación comunicativa. La comunicación interpersonal crea "la intersubjetividad donde podemos percibir ciertos fenómenos que escapan al conocimiento del yo, pues el sujeto no puede percibir su experiencia inmediata pero sí percibe las de los otros, en tanto le son dadas como aspectos del mundo social" (Rizo, 2014, p. 298).

Los actores-investigadores que se insertan en medios ambientes naturales de la vida cotidiana para intervenir en procesos comunicativos acuden a "la reflexividad, como cuestionamiento crítico de la modernidad, apuesta por la recuperación del sujeto en los procesos de generación del conocimiento, tanto del investigador en su calidad de observador-conceptualizador como del sujeto investigado" (Díaz, 2018, p. 13).

El reto metodológico es el diseño de una práctica de investigación etnometodológica que acerque la actuación de los actores-investigadores-emisores a las condiciones naturales de la vida cotidiana y permita al mismo tiempo la reflexividad de los actores-investigadores sobre el proceso comunicativo realizado.

El objetivo es conocer el comportamiento y la capacidad reflexiva de los actores-investigadores femeninos y masculinos como selectores de noticias mediáticas sobre cambio climático y emisores de publicaciones en Facebook.

\section{Metodología}

Entrar en el terreno epistemológico del cómo obtener datos para estudiar el fenómeno comunicativo del cambio climático exige creatividad y apertura al diseño de nuevas prácticas de investigación cualitativa aplicándose la etnometodológía como "trabajo de campo en la comunidad para comprender la realidad de sus habitantes, (...) carácter empírico (...) observación participante, (...) y experimentos, (...) deducir comportamientos, estilos de vida, jerarquías en la comunicación a partir de la cotidianidad" (Díaz, 2018, p. 13). Todos estos elementos aportan herramientas para el investigador cualitativo. Como técnica se aplicó la etnografía que busca "el conocimiento del modo de vida de una unidad social concreta: a través de un escrito que retrata los valores, ideas, prácticas y modos de vida del grupo cultural en cuestión" (Alonso, 2007, p. 123). Con la finalidad de llevar el registro del proceso comunicativo virtual en Facebook siguiendo el experimento creado ex profeso que ejecutaron los actores-investigadores masculino y femenino.

El procedimiento fue seleccionar dos tesistas de la Maestría en Comunicación, de la Facultad de Derecho y Ciencias Sociales de la Universidad Autónoma de Tamaulipas; un hombre y una mujer, cada uno de ellos actuaría como receptores y seleccionadores de mensajes de medios masivos de comunicación de notas relacionadas con el cambio climático a nivel nacional, eligiendo tres notas diferentes diarias que publicarían a sus 12 receptores directos en la red social digital de Facebook.

Se experimentó el diseño de la práctica etnometodológica, donde los actores-investigadores propusieron los instrumentos de registro de publicaciones y reacciones cognitivas-afectivas de los propios actores-investigadores y de los contactos directos e indirectos, conforme al calendario de actividades.

Se aplicó la técnica de la observación participante por lo que cada actor-investigador eligió a sus 12 receptores 
directos entre sus conocidos para "superar la etapa en la cual el investigador aparece ante los actores sociales como alguien de afuera y convertirse en la medida de lo posible en un miembro competente de la comunidad, siendo capaz de interpretar e implementar sus reglas" (Rosenberg, 2017, p. 92) $\mathrm{o}$, incluso, de cuestionarlas, romperlas u omitirlas, mediante la creación de experiencias disruptivas que provoquen un cambio en la comunicación, fuera de las expectativas dictadas por el sentido común del mundo de la cotidianidad como propone la etnometodología.

\subsection{Muestra: formación de grupos de receptores directos en Facebook}

Cada actor-investigador usó su propia cuenta en Facebook, para publicar las notas seleccionadas sobre el cambio climático y eligió entre sus conocidos en Facebook a seis hombres y seis mujeres, quienes formaron el grupo de receptores directos, los receptores indirectos fueron aquellos que contestaron y opinaron sobre las publicaciones y que no estuvieron seleccionados. Para los actores-investigadores su grupo de contactos directos era percibido como personas con quienes deseaban quedar bien y mantener una comunicación virtual que fuera aprobada por el receptor. "El conjunto de sus contactos en Facebook, (...) representa un acervo, una posibilidad, un capital relacional. En realidad, lo más preciado es la constancia de relaciones con un número reducido de contactos" (Amigo et al., 2016, p. 132).

\section{Reacciones cognitivas y afectivas}

Hombre. Fue difícil la elección de los receptores directos: sabíamos del riesgo de perder un contacto dentro de nuestra lista de amigos en la red social Facebook. Me tocó ser eliminado por varios receptores, lo cual me causó gran conmoción.

Mujer. El 28 de agosto elegí cuidadosamente mis receptores directos, no quise escoger amigos cercanos ya que pensaba que así tendría una respuesta más natural. El primero de septiembre tuve que elegir a otro receptor, ya que me eliminó uno de ellos, fácilmente decidí. Al día siguiente me sentí feliz de que mi nuevo receptor, haya reaccionado de buena manera, comentó e interactuó con las publicaciones.
Los actores-investigadores mostraron temor a ser rechazados por sus receptores directos. Esta situación provocó incertidumbre, dudas, frustración y deseo de abandonar la práctica en el hombre porque eligió trabajar con amigos; en cambio, para la mujer resultó más sencillo porque eligió receptores que no eran amigos cercanos, por lo cual no temía ser rechazada.

\subsection{Diseño de instrumentos}

Se diseñaron tres instrumentos para el registro de procesos comunicativos vivenciados por los actores-investigadores y sus receptores directos e indirectos: diario del emisor, diario del receptor y diario de campo del actor-investigador.

a) Diario del emisor: registra los procesos de búsqueda de las notas mediáticas sobre el cambio climático y la justificación de la elección de las noticias para su publicación en Facebook. Las variables fueron el número de búsqueda (día, semana, mes y hora). Lugar (casa, oficina, escuela, otro). Dispositivo de obtención de la información (celular, computadora, laptop, tableta). Medio de comunicación (televisión, radio, prensa, blog, red social, revista, página web, portal). Links visitados no elegidos y motivo de rechazo. Links de información seleccionada, información elegida y motivo de selección. Publicación (título, autor, tema, fenómeno natural). Actores noticiosos (ciudadanos, científicos, empresas privadas, gobernantes, ONG, animales, vegetación, otros). Lugar geográfico (el propio Tamaulipas, dónde, otros, cuáles). Nombres del medio. Soporte del mensaje (texto, foto, audio, video, gráfico, otro, cuál). Tipo de mensaje (nota periodística, boletín pagado, anuncio, crítica, artículo, documental, comentario, reportaje). Asuntos del mensaje (avisos, acciones de gobierno, leyes, políticas públicas, manifestaciones ciudadanas, demandas, denuncias, descubrimientos científicos, otros). Captura de pantalla del mensaje seleccionado (audio, imágenes). Conversación entre receptores directos e indirectos.

b) Diario del receptor: especifica las respuestas obtenidas de receptores directos e indirectos a las publicaciones en Facebook. Las variables fueron: nombre del receptor (sexo, edad, nivel educativo). Relación con el emisor (pariente, amigo, compañero de trabajo, pareja, conocido 
en la web). Comentario (día, semana, mes y hora). Lugar (casa, oficina, escuela, otro). Captura de pantalla de la publicación. Transcripción literal del comentario o conversación mantenida. Reacciones de receptores (género, número de likes, comentarios y shares o porcentaje de audiencia). Emoticones (me gusta, me encanta, me divierte, me alegra, me asombra, me entristece, me enfada). Lenguaje (formal, informal, amable, burlón y divertido). El receptor conoce el tema, lo ignora, muestra interés o rechazo.

\section{Reacciones cognitivas y afectivas}

Hombre. Fue difícil el llenado de instrumentos, tenía que monitorear las publicaciones y capturar pantalla por si surgía algún descontento y se eliminaba dicha publicación, tenía que registrarlo, de lo contrario no se podría saber si realmente se había cumplido con la publicación en el muro de algún receptor directo.

c) Diario de campo del actor-investigador: los emisores registran sus procesos cognitivos y afectivos durante la práctica etnometodológica.

\section{Reacciones cognitivas y afectivas}

Hombre. La primera dificultad fue la elaboración de los instrumentos, se trabajó sobre prueba y error al estar presentando una propuesta y siendo modificada tras una lluvia de ideas en el grupo. Surgió en mi persona un sentimiento de desconcierto y algo de intriga sobre una posible respuesta negativa de los receptores directos.

El actor-investigador hombre asumió el papel de líder al diseñar los instrumentos para el estudio. La sistematización es una habilidad desarrollada en el cerebro masculino. "El sistematizador es capaz de averiguar intuitivamente cómo funcionan las cosas, o de extraer las reglas fundamentales que gobiernan el comportamiento de un sistema" (Baron, 2005, p. 17). La mujer actora-investigadora no participó en el proceso de creación de los instrumentos, se limitó a aceptar las propuestas realizadas por el actor-investigador masculino y ponerlas en práctica. El cerebro femenino por su parte desarrolla la habilidad de la empatía. "Las mujeres suelen valorar más el desarrollo de unas relaciones altruistas y recíprocas, para las que se requiere una buena habilidad de empatía" (Baron, 2005, p. 47).

\section{Resultados}

\subsection{Proceso de búsqueda y selección de noticias sobre el cambio climático}

La práctica etnometodológica parte de la idea que cada vez que se construye una experiencia disruptiva que interrumpe la normalidad y cambia el proceso de las rutinas comunicativas los sujetos se ven forzados a reflexionar sobre su propia experiencia de vida y a poner atención en los detalles que antes pasaban desapercibidos. Para los actores-investigadores buscar noticias sobre el cambio climático fue una experiencia nueva, ya que desconocían del tema y no era de su interés antes de iniciar esta práctica.

\section{Reacciones cognitivas y afectivas}

Hombre. Para ser sincero, uno no tiene conocimiento de dónde obtener información de publicaciones sobre el cambio climático. Fue cuestión de tiempo identificar los medios que publican sobre el cambio climático, si eran notas, o si tenían fotografías o videos.

Se observa la formación de un mecanismo de aprendizaje en la rutina de búsqueda de notas informativas mediáticas sobre el cambio climático en los actores-investigadores a lo largo de la práctica etnometodológica.

\subsection{Temáticas de notas periodísticas sobre el cambio climático publicadas y compartidas en Facebook por emisor femenino y masculino}

Las personas experimentan el cambio climático de forma simbólica mediante mensajes recibidos vía medios de comunicación y experimentalmente al sufrir las inclemencias y daños por fenómenos del cambio climático, en este estudio se pone atención a los mensajes mediáticos porque "los cambios medioambientales, que se experimentan solo indirectamente a través de la ciencia, las opiniones y actitudes del público, son fundamentalmente el resultado de reacciones cognitivas y afectivas ante un entorno simbólico" (Peters y Heinrichs, 2009, p. 61).

Cada emisor publicó 63 noticias sobre el cambio climático en el muro de Facebook de sus 12 receptores directos, dando un total de 126 publicaciones.

El emisor femenino tuvo la concentración más alta con el $37.30 \%$ de la información divulgada en Facebook en 
Tabla 1. Notas mediáticas publicadas en Facebook sobre el cambio climático

\begin{tabular}{|c|c|c|c|c|c|c|}
\hline \multirow[t]{2}{*}{ Temática } & \multicolumn{2}{|c|}{$\begin{array}{c}\text { Emisor } \\
\text { Femenino }\end{array}$} & \multicolumn{2}{|c|}{$\begin{array}{c}\text { Emisor } \\
\text { Masculino }\end{array}$} & \multicolumn{2}{|c|}{ Total } \\
\hline & Frec. & $\%$ & Frec. & $\%$ & Frec. & $\%$ \\
\hline Cambio climático & 17 & 13.49 & 9 & 7.14 & 26 & 20.63 \\
\hline Contaminación & 20 & 15.87 & 5 & 3.96 & 25 & 19.84 \\
\hline Políticas públicas C.C. & 5 & 3.96 & 12 & 9.52 & 17 & 13.49 \\
\hline Investigación C.C. & 0 & 0 & 8 & 6.34 & 8 & 6.34 \\
\hline Sequía & 5 & 3.96 & 1 & 0.79 & 6 & 4.76 \\
\hline Incendios & 2 & 1.58 & 4 & 3.17 & 6 & 4.76 \\
\hline Derrames de tóxicos & 0 & 0 & 5 & 3.96 & 5 & 3.96 \\
\hline Reforestación & 3 & 2.38 & 1 & 0.79 & 4 & 3.17 \\
\hline Huracán & 1 & 0.79 & 3 & 2.38 & 4 & 3.17 \\
\hline Sismos & 3 & 2.38 & 0 & 0 & 3 & 2.38 \\
\hline Conservación ambiental & 2 & 1.58 & 1 & 0.79 & 3 & 2.38 \\
\hline Calentamiento global & 1 & 0.79 & 2 & 1.58 & 3 & 2.38 \\
\hline Animales en peligro & 0 & 0 & 3 & 2.38 & 3 & 2.38 \\
\hline Aviso protección civil & 0 & 0 & 3 & 2.38 & 3 & 2.38 \\
\hline Desastres naturales & 2 & 1.58 & 0 & 0 & 2 & 1.58 \\
\hline Inundación & 0 & 0 & 2 & 1.58 & 2 & 1.58 \\
\hline Tormenta tropical & 1 & 0.79 & 1 & 0.79 & 2 & 1.58 \\
\hline Daño ambiental & 1 & 0.79 & 0 & 0 & 1 & 0.79 \\
\hline Plagas & 0 & 0 & 1 & 0.79 & 1 & 0.79 \\
\hline Uso de la electricidad & 0 & 0 & 1 & 0.79 & 1 & 0.79 \\
\hline Baja presión atmosférica & 0 & 0 & 1 & 0.79 & 1 & 0.79 \\
\hline Total de publicaciones & 63 & 50 & 63 & 50 & 126 & 100 \\
\hline
\end{tabular}

Fuente: Elaboración propia

cuatro temáticas: compartió veinte notas $(15.87 \%)$ sobre contaminación, diecisiete $(13.49 \%)$ sobre cambio climático y cinco $(3.96 \%)$ sobre los temas de políticas públicas para el cambio climático y sequía, respectivamente.

El emisor masculino concentró el $30.95 \%$ de la información divulgada en Facebook en cinco temáticas: doce notas $(9.52 \%)$ sobre políticas públicas para el cambio climático, nueve $(7.14 \%)$ sobre el cambio climático, ocho $(6.34 \%)$ referentes a la investigación sobre el cambio climático y cinco $(3.96 \%)$ sobre contaminación y derrames con fugas de sustancias toxicas, respectivamente.

Existió una dispersión temática en la información difundida por el emisor femenino del $62.7 \%$ con nueve temáticas: con tres notas $(2.38 \%)$ reforestación y sismos; con dos $(1.58 \%)$ incendios, conservación del medio ambiente y desastres naturales; y con una sola nota $(0.79 \%)$ los temas de huracán, calentamiento global, tormenta tropical y daño ambiental.
La dispersión en la información difundida en Facebook por el emisor masculino fue más alta, con el $69.05 \%$ correspondiente a trece temáticas: con cuatro notas $(3.17 \%)$ incendios; con tres $(2.38 \%)$ huracán, animales en peligro, avisos de protección civil; con dos $(1.58 \%)$ calentamiento global e inundación; y con una sola nota $(0.79 \%)$ reforestación, conservación del medio ambiente, tormenta tropical, plagas, uso de la electricidad y baja presión atmosférica.

De las 63 publicaciones sobre el cambio climático efectuadas en Facebook, el emisor femenino se concentró en trece temáticas otorgando relevancia a la contaminación, el cambio climático, las políticas públicas y la sequía. El emisor masculino mostró mayor dispersión con dieciocho temáticas, destacando políticas públicas, cambio climático, investigación, contaminación y derrames tóxicos. 


\subsection{La experiencia disruptiva de publicar en el muro del receptor noticias sobre el cambio climático}

En la etnometodología "Garfinkel centra su estudio en la comprensión de cómo es posible que los seres humanos constituyan normas que pueden seguir o romper" (Mesa, 2010, p. 8). Los actores-investigadores señalaron en ocasiones sentirse como invasores al publicar información sobre cambio climático en el muro de sus receptores directos para provocar una experiencia disruptiva que motivará la reacción estudiada, debido a que "la etnometodología aboga por el reconocimiento de la capacidad reflexiva e interpretativa de las personas, entendiendo que son los elementos modificadores de la sociedad mediante el cambio de las normas que esta se da" (Marqués y López, 2017, p. 376).

\section{Reacciones cognitivas y afectivas}

Hombre. No esperaba que el bombardeo de notas incomodara, más si aportaban conocimiento del diario vivir y precauciones que debemos tomar. Me espanté y dejé de publicar dos días, después realicé publicaciones esporádicas con nuevos receptores que sustituyeron a los que habían mostrado hartazgo hacia la repetitiva publicación.

Mujer. La primera publicación logró el interés de dos personas. Los demás pensaron que yo tenía virus, y comenzaron a preguntar que por qué estaba publicando en su muro. Se sintieron amenazados, invadidos en su espacio personal. Tuve ganas de dejar de publicar en su muro. Creí que no iba a funcionar, por la muy mala respuesta y me preguntaba ¿por qué? si solo eran noticias sobre el cambio climático. Luego realicé menos publicaciones, tenía temor de su reacción y no quería molestarlos al invadir su privacidad.

Para ambos actores-investigadores era importante mantener una buena imagen en su comunicación en Facebook con sus contactos directos y existía temor a perderla. "Las redes sociales tales como Facebook ofrecen más oportunidades para la comparación social que los contextos cara a cara. Por esto el manejo de la impresión (impression management) es un aspecto importante de las presentaciones online" (Oberst et al., 2016, p. 88).

\subsection{La experiencia reflexiva del actor-investigador}

"La comprensión de todo fenómeno o cambio social debe partir en primer lugar del autoconocimiento del observador, que siempre está mediado por el contexto cultural, simbólico y normativo" (Garro, 2017, p. 639). Romper la rutina comunicativa con los contactos en Facebook al publicar noticias sobre el cambio climático causó desconcierto en emisores y receptores. Los actores-investigadores reaccionaron ante las respuestas de indiferencia y rechazo de sus contactos directos e indirectos con asombro, ante el desconocimiento detectado del tema de los fenómenos asociados al cambio climático y el poco interés mostrado por conocer información sobre este tema por parte de los receptores directos.

\section{Reacciones cognitivas y afectivas}

Hombre. Los receptores directos se prestaron las publicaciones para entablar discusiones o pequeños debates, incluso con usuarios que no eran los directos y que ni siquiera yo tenía en mi lista de receptores, algunos usaron emoticones.

Mujer. Me desconcertaron las reacciones de los receptores, aunque a mí no me eliminaron al principio, pero a otro compañero sí. Nos parecían medidas muy extremas y nos sentíamos mal de estar invadiendo su espacio y publicando en su muro. Algunos receptores rechazaban la información borrándola, otros le daban me gusta, otros no comentaban nada. Me sentí tranquila, luego me sacó de onda ser eliminada de Facebook, por el receptor que había estado borrando continuamente las publicaciones, no esperaba que me eliminara tan pronto.

"La seguridad ontológica se construye a partir de lo estable y rutinizado, de lo predecible, y la velocidad del cambio opera en el sentido opuesto" (Amigo et al., 2016, p.130). Al cambiar su rutina comunicativa en Facebook los actores-investigadores salieron de su zona de confort y enfrentaron la incertidumbre ante las posibles reacciones de sus contactos. Los receptores directos mostraron rechazo al inicio de la práctica, no les interesó el tema del cambio climático y tardaron en responder positivamente y participar con comentarios. El actor-investigador masculino, después de superar el rechazo, experimentó aceptación e inclusión 
de nuevos contactos; en cambio, la actora-investigadora enfrentó la inseguridad y el rechazo ajeno con asertividad, al considerarlo como parte del resultado del estudio.

\subsection{Proceso de publicación}

Para la realización de la práctica etnometodológica se siguió un calendario de una semana de publicaciones con dos semanas intermedias de receso, repitiéndose el proceso tres veces, iniciando el 28 de agosto y concluyendo el 29 de octubre del 2016.

Semana 1 (28 agosto al 3 de septiembre)

Los actores-investigadores retransmiten a sus contactos directos en Facebook un mensaje mediático sobre el cambio climático cada tres horas (tres mensajes al día en total) de notas de medios masivos nacionales, registrando todo en el diario de campo y haciendo impresión de pantalla de mensajes enviados y recibidos.

\section{Reacciones cognitivas y afectivas}

Hombre. Los receptores comenzaron a reaccionar (en buena o mala manera), pero empezaban a comentar.

Mujer. Los receptores han tenido mejor reacción en cuanto a las publicaciones, tres hombres han interactuado más con las noticias, esto me hace sentir bien ya que he estado algo preocupada de que un receptor me vuelva eliminar.

El tema del cambio climático en las noticias está fuera del interés observado en los jóvenes de ambos géneros y se presenta como algo nuevo, desconocido e incluso rechazado. "Si se presentan diferencias por los distintos tipos de información en función del género. Los hombres muestran como primera opción las noticias de deportes mientras las mujeres optan por la información sobre sociedad, cultural y comunicación” (García et al., 2015, p. 610).

Semanas 2 y 3 (4 al 17 de septiembre)

Los actores-investigadores no envían ni publican en Facebook mensajes sobre el cambio climático, se limitan a recibir mensajes de sus receptores directos e indirectos, registran todo en su diario de campo y hacen impresión de pantalla de los mensajes recibidos.

\section{Reacciones cognitivas y afectivas}

Hombre. Tenía que estar monitoreando las publicaciones y capturando pantalla por si surgía algún descontento y se eliminaba dicha publicación.

Mujer. Realmente han sido pocos los usuarios que han interactuado con las noticias. Me atrasé dos días, pero cumplí todas las publicaciones. Sentí alivio, quería terminar la primera semana, me sentía agobiada por las reacciones de los receptores. Me sentí liberada de no tener que molestar con mis publicaciones.

Semana 4 (18 al 24 de septiembre)

Los actores-investigadores reinician publicaciones en Facebook. En México, el 19 de septiembre se conmemoran los sismos de 1985, es el día de la Protección Civil y se realizan simulacros de sismos en todo el país, así como eventos relacionados con prevención de riesgos ante fenómenos del cambio climático, lo que motivó un incremento en las notas informativas relacionadas con el tema.

\section{Reacciones cognitivas y afectivas}

Mujer. Comencé con ánimo, no quería sentirme mal por publicar en el muro de otras personas por temor a enojos. Recibí mejor respuesta. Una usuaria comenzó a interactuar con las publicaciones, eso me causó sorpresa y alegría. Fue curioso que receptores indirectos comentaron e interactuaron con ciertas publicaciones y cómo mis receptores directos no lo hacían, e incluso borraron las publicaciones. Me di cuenta de que, ni incitándolos a responder algo sobre la noticia, funcionaba. Dejé el estrés, y más tranquila, permití que los receptores interesados siguieran interactuando y los que estuvieron borrando las publicaciones lo siguieron haciendo.

Semanas 5 y 6 (25 de septiembre al 8 de octubre)

Los actores-investigadores no envían ni publican en Facebook mensajes sobre el cambio climático, se limitan a recibir mensajes de sus receptores seleccionados y los voluntarios que participen

\section{Reacciones cognitivas y afectivas}

Mujer. Pasé dos semanas sin publicar nada, y las aproveché en llenar los diarios de campo que, siendo sincera, me 
estresaban porque era demasiada información de los 12 receptores.

Semana 7 (9 al 15 de octubre)

El actor-investigador envía mensaje cada tres horas (tres mensajes al día en total) sobre nota de medios masivos de comunicación, relativas al cambio climático.

\section{Reacciones cognitivas y afectivas}

Mujer. Al final solo interactuaban las personas que realmente estaban interesadas, vi muy poco interés. Al principio me estresaba y me esforzaba más por llamar su atención, haciéndoles comentarios directos, la mayoría no me respondía. Y a estas instancias dejé de preocuparme, ellos debían reaccionar según su criterio.

Semanas 8 y 9 (16 al 29 de octubre)

Los actores-investigadores no envían ni publican en Facebook mensajes sobre el cambio climático, se limitan a recibirlos.

\section{Reacciones cognitivas y afectivas}

Mujer. No recordé publicar noticias hasta como a las seis de la tarde. Realicé esa publicación y no volví a realizar otra, lo olvidé por completo. En la noche recordé que solo había publicado una nota y me sentí frustrada. Al terminar la tercera semana me sentí feliz.

Hombre. Realicé un periodo extra de publicaciones para recuperar las que por descuido o temor no había realizado. Lo más difícil es hacer el análisis total de las publicaciones realizadas.

En el uso de Facebook, mujeres y hombres muestran diferencias. "En el entorno virtual ellos expresan con más libertad sus sentimientos. (...) Los chicos solo fueron superiores en número a la hora de compartir enlaces. Ellas compartieron más videos musicales y noticias de actualidad. Ellos también compartieron noticias de actualidad" (Martínez, 2013, p. 84). Los actores-investigadores cumplieron con todas las publicaciones, aunque en ocasiones no siguieron el calendario propuesto. La mujer mostró una actitud de aceptación al rechazo, indiferencia y atención por parte de sus receptores directos e indirectos a las notas del cambio climático publicadas en Facebook, mientras que el hombre se preocupó más por no ser rechazado por sus receptores directos.

\section{Conclusiones}

La práctica etnometodológica propuesta se probó con éxito, puesto que los actores-investigadores siguieron todas las instrucciones propuestas. Es relevante destacar el estado afectivo de incertidumbre, desconcierto y temor por las experiencias disruptivas de comunicación que estaban practicando los actores-investigadores durante el proceso etnometodológico y la poca respuesta recibida, e incluso el rechazo de los receptores directos en el estudio de la recepción de notas mediáticas sobre el cambio climático en la red social Facebook.

En las 126 publicaciones realizadas existió una alta concentración temática en pocos fenómenos asociados al cambio climático por el emisor femenino y una gran dispersión temática en las publicaciones efectuadas por el emisor masculino. Los temas más replicados por la mujer fueron contaminación y cambio climático, para el hombre los temas más publicados fueron políticas públicas, cambio climático e investigación. El actor-investigador masculino se destacó por la sistematización del estudio al diseñar los instrumentos y mostró incertidumbre en el proceso comunicativo virtual en Facebook al buscar ser aceptado y temer el rechazo de sus contactos directos, al publicarles noticias sobre cambio climático.

La actora-investigadora se limitó a aplicar el instrumento y a seguir instrucciones, asumió la práctica comunicativa virtual como un experimento y observó las reacciones de sus contactos con distancia emocional, lo que le permitió aceptar con empatía el rechazo al ejercicio. Es necesario realizar nuevas pruebas para lograr la validación de esta práctica.

\section{Referencias}

Alonso, G. (2007). Metodología cualitativa y formación intercultural en entornos virtuales. Teoría de la Educación. Educación y Cultura en la Sociedad de la Información, 8(1)106-133. Recuperado de http://www. redalyc.org/articulo.oa? $\mathrm{id}=201017309007$

Amigo, B., Bravo, C. y Osorio, F. (2016) Telefonía móvil inteligente e hiper cotidianidad. Athenea Digital, 
16(2),115-137. Recuperado de http://atheneadigital.net /article/view/v16-n2-amigo-bravo-osorio

Arellano, H. (2014). Cambio Climático y Sociedad, MAPorrúa librero-editor, México. Recuperado de ri.uae mex.mx/handle/20.500.11799/59155

Baron, C. (2005). La gran diferencia. Cómo son realmente los cerebros de hombres y mujeres, Barcelona: Editorial Amat. Recuperado de https://dialnet.unirioja.es/servlet/ libro? codigo $=255479$

Builes, V. y Gutiérrez, T. (2017). Aportes al concepto de realidad: punto de partida para la transformación de sistemas. Revista Universidad Católica Luis Amigó, (1),262-275. Recuperado de www.funlam.edu.co/revistas/index.php/RULuisAmigo /article/download/2659/2023

Carvalho, A. (2009). Relectura de noticias sobre cambio climático. Culturas ideológicas y discursos mediáticos sobre la ciencia. Inforamérica, 25-47. Recuperado de https://www.infoamerica.org/icr/n01/infoamerica0 1_carvalho.pdf

Díaz, M. (2018). Tendencias epistemológicas en torno a la acción navegante del sujeto. Espiral, Estudios sobre Estado y Sociedad, 25(72), 9-34. Recuperado de http://espiral.cucsh.udg.mx/index.php/EEES/article/ viewFile/6999/6069

Fernández, F. y Tardivo, G. (2016). La Sociología de la Comunicación y la Mass Comunication Research. Tradición y actualidad. Espacio Abierto. Cuaderno Venezolano de Sociología, 25(3),133-142. Recuperado de www.redalyc.org/pdf/122/12249678009.pdf

García, C., García, J. y Montes, V. (2015). Jóvenes y consumo de noticias a través de Internet y los medios sociales. Historia y Comunicación Social, 20(2), 601-619. Recuperado de http://revistas.ucm.es/index.ph p/HICS/article/view/51402

Garro, G. (2017). Relación, razón relacional y reflexividad: tres conceptos fundamentales de la sociología relacional. Revista Mexicana de Sociología, 79(3),633-660. Recuperado de http://www.scielo.org.mx/scielo.php?script=sci_arttext \&pid=S0188-25032017000300633\&lng=es\&tlng=en.

Martínez, V. (2013). Facebook y los jóvenes universitarios: qué comunican según el género. Historia $y$ Comunicación Social, 79 (18), 77-87. Recuperado de http://revistas.ucm.es/index.php/HICS/article/viewFil e/44313/41871

Marqués, P. y López, J. (2017). Bases teóricas de la Ecología Humana de la Comunicación. Del verbo al bit, 364-384. Cuadernos Artesanos de Comunicación / 116. Revista Latina. Recuperado de http://www.revistalatinacs.org/ 16SLCS/libro-colectivo-edicion-2.html

Mesa, A. (2010) Estudio etnometodológico del uso cotidiano de los videojuegos. Memoria VII Congreso Iberoamericano de Psicología. Oviedo, España.
Recuperado de http://www.academia.edu/487318/Estu dio_etnometodol\%C3\%B3gico_del_uso_cotidiano_d e_los_videojuegos

Oberst, U., Chamarro, A. y Renau, V. (2016) Estereotipos de género 2.0: Auto-representaciones de adolescentes en Facebook. Comunicar, 48(XXIV),81-90. Recuperado de https://www.revistacomunicar.com/verpdf.php?num ero $=48 \&$ articulo $=48-2016-08$

Peters, P. y Heinrichs, H. (2009). El cambio climático en los medios alemanes. Legitimación de la política climática, Infoamérica, 59-78. Recuperado de https://dialnet.unir ioja.es/servlet/articulo?codigo $=3908263$

Piñuel, J., Gaitán, J. y Lozano, A. (2011). Metodología para el análisis de la incertidumbre: un diseño de "Phillips 66" en el estudio de la percepción social de los riesgos vinculados al CC. Actas III Congreso Internacional Sociedad Latina de Comunicación Social, Universidad de la Laguna, 1-20. Recuperado de www.revistalatinacs. org/11SLCS/actas_2011_IIICILCS/045.pdf

Retamal, M., Rojas, J. y Parra, O. (2011). Percepción al cambio climático y a la gestión del agua: aportes de las estrategias metodológicas cualitativas para su comprensión. Ambiente \& Sociedade, 14(1), 175-194. Recuperado de http://www.scielo.br/scielo.php?pid=S 1414-753X2011000100010\&script=sci_arttext

Rizo, G. (2014). De lo interpersonal a lo intersubjetivo. Algunas claves teóricas y conceptuales para definir la comunicación intersubjetiva. Quórum Académico, 11(2),290-307. Recuperado de http://www.redalyc.org/ comocitar.oa?id=199032627007

Rosenberg, L. (2017). Etnografía del trabajo periodístico. Apuntes sobre la inserción del investigador en la sala de redacción de un diario argentino. Comunicación y Sociedad, (28),87-109. Recuperado de http://www.scielo.org.mx/pdf/comso/n28/0188-252Xcomso-28-00087.pdf

Sabido, R. (2016). Cuerpo y sentidos: el análisis sociológico de la percepción. Revista Debate Feminista, 51,63-80. Recuperado de http://www.debatefeminista.cieg.unam. $\mathrm{mx} / \mathrm{wp}$-content/uploads/2016/03/articulos/051_05.pdf

Salcedo, Ch. (2015). Sociología. Huancayo: Fondo Editorial de la Universidad Continental. Recuperado de http: //repositorio.continental.edu.pe/bitstream/continental/2 211/1/DO_FCE_FH_313_501_MT_UC0815_20162

Sánchez, G. y Fele, G. (2015). Normatividad en deporte: una reespecificación etnometodológica. EMPIRIA, Revista de metodología en las Ciencias Sociales, (30),13-31. Recuperado de http://www.redalyc.org/articulo.oa?id= 297135368001

Vela, D. y Cantamutto, L. (2016). De participante a observador: el método etnográfico en el análisis de las interacciones digitales de Whatsapp.Tonos Digitales, (31),1-22. Recuperado de www.tonosdigital.es/ojs/inde x.php/tonos/article/download/1531/874 
Vizer, A. (2003). La trama (in)visible de la vida social: comunicación, sentido y realidad. Buenos Aires: La Crujía Ediciones. Recuperado de https://es.scribd.com/document/81595671/VizerLa-Trama-Invisible-de-La-Vida-Social-CAP-V 